\title{
The IRHUM (Isotopic Reconstruction of Human Migration) database - bioavailable strontium isotope ratios for geochemical fingerprinting in France
}

\author{
M. Willmes ${ }^{1}$, L. McMorrow ${ }^{1}$, L. Kinsley ${ }^{1}$, R. Armstrong ${ }^{1}$, M. Aubert ${ }^{1, *}$, S. Eggins ${ }^{1}$, C. Falguères ${ }^{2}$, \\ B. Maureille ${ }^{3}$, I. Moffat ${ }^{1,4}$, and R. Grün ${ }^{1}$ \\ ${ }^{1}$ The Australian National University, Research School of Earth Sciences, Canberra 0200, ACT, Australia \\ ${ }^{2}$ Département de Préhistoire, Muséum National d'Histoire Naturelle, UMR7194 du CNRS, Paris, France \\ ${ }^{3}$ University of Bordeaux, CNRS, MCC, PACEA UMR5199, 33400, Talence, France \\ ${ }^{4}$ Flinders University, Department of Archaeology, Adelaide, 5000, SA, Australia \\ *now at: University of Wollongong, School of Earth and Environmental Sciences, Centre for Archaeological \\ Science, Wollongong 2522, NSW, Australia
}

Correspondence to: M. Willmes (malte.willmes@anu.edu.au)

Received: 5 November 2013 - Published in Earth Syst. Sci. Data Discuss.: 25 November 2013

Revised: 13 February 2014 - Accepted: 24 February 2014 - Published: 25 March 2014

\begin{abstract}
Strontium isotope ratios $\left({ }^{87} \mathrm{Sr} /{ }^{86} \mathrm{Sr}\right)$ are a key geochemical tracer used in a wide range of fields including archaeology, ecology, food and forensic sciences. These applications are based on the principle that the $\mathrm{Sr}$ isotopic ratios of natural materials reflect the sources of strontium available during their formation. A major constraint for current studies is the lack of robust reference maps to evaluate the source of strontium isotope ratios measured in the samples. Here we provide a new data set of bioavailable $\mathrm{Sr}$ isotope ratios for the major geologic units of France, based on plant and soil samples (Pangaea data repository doi:10.1594/PANGAEA.819142). The IRHUM (Isotopic Reconstruction of Human Migration) database is a web platform to access, explore and map our data set. The database provides the spatial context and metadata for each sample, allowing the user to evaluate the suitability of the sample for their specific study. In addition, it allows users to upload and share their own data sets and data products, which will enhance collaboration across the different research fields. This article describes the sampling and analytical methods used to generate the data set and how to use and access the data set through the IRHUM database. Any interpretation of the isotope data set is outside the scope of this publication.
\end{abstract}

\section{Introduction}

Strontium isotope ratios $\left({ }^{87} \mathrm{Sr} /{ }^{86} \mathrm{Sr}\right)$ can be used as a geochemical tracer in a wide range of fields, including archaeology (Bentley, 2006; Slovak and Paytan, 2011), ecology (Hobson et al., 2010), food (Kelly and Heaton, 2005; Voerkelius et al., 2010) and forensic sciences (Beard and Johnson, 2000). The Sr isotopic ratios of natural materials reflect the sources of strontium available during their formation. $\mathrm{Sr}$ isotope ratios in bedrock are a function of age and composition of the rock and thus vary between geologic units (Faure and Mensing, 2005). Through weathering Sr is released and transported into the soil, ground and surface water, where it becomes available for uptake by plants and eventually enters the food cycle (Bentley, 2006; Capo et al., 1998). Due to their large atomic mass, $\mathrm{Sr}$ isotope ratios $\left({ }^{87} \mathrm{Sr} /{ }^{86} \mathrm{Sr}\right)$ are not measurably affected by kinetic and equilibrium fractionations during processes at low temperatures and biologic processes (Faure and Mensing, 2005). The isotopic composition of bioavailable $\mathrm{Sr}$ (the $\mathrm{Sr}$ taken up into the food cycle) can differ from the bulk $\mathrm{Sr}$ isotopic composition of the bedrock, mainly through the preferential weathering of different minerals (Sillen et al., 1998). However, the 
bioavailable $\mathrm{Sr}$ isotope ratios can also be influenced by processes like precipitation, dry fall, sea spray, and in modern context by fertiliser application (Bentley, 2006; Evans et al., 2010; Frei and Frei, 2013; Maurer et al., 2012; Price et al., 2002; Slovak and Paytan, 2011). In addition, the range of $\mathrm{Sr}$ isotope compositions varies not only laterally between different regions, but also with depth and time as the local environmental conditions change. In summary, a direct connection exists between the measured $\mathrm{Sr}$ isotope ratio of a material and its source region, but determining the $\mathrm{Sr}$ isotope composition of different regions is complicated by the diverse range of possible influences on the bioavailable $\mathrm{Sr}$ isotope ratio composition.

\section{Mapping strontium isotopes}

The choice of sample material to constrain the bioavailable isotope ratio is a fundamental consideration and is discussed in detail in the literature (Bentley, 2006; Maurer et al., 2012; Price et al., 2002; Slovak and Paytan, 2011). In general three different approaches can be distinguished.

1. Fauna or human samples that are local to a region are considered to represent a robust average bioavailable $\mathrm{Sr}$ isotope composition over their feeding area (Bentley, 2006; Price et al., 2002). However, these samples are restricted in their availability in the context of a country wide study. In addition, fossil samples are subject to diagenetic overprint, while modern samples might be influenced by non-local food sources and fertiliser (Bentley, 2006; Maurer et al., 2012).

2. The bioavailable $\mathrm{Sr}$ isotope ratio for different geologic units can be determined by analysing a number of soils, plants, ground and surface waters (Evans et al., 2010; Hodell et al., 2004; Maurer et al., 2012; Price et al., 2002; Sillen et al., 1998). Overall, surface and groundwater samples provide a good estimate of the bioavailable Sr isotope signal over their catchment area, but are influenced by seasonal changes and changes in precipitation (e.g. Shand et al., 2009). Soils and plants average $\mathrm{Sr}$ over a very small area and are readily available in many different environments and easily analysed. The use of soil leachates to determine the local bioavailable Sr isotope ratio has shown varying degrees of success in different regions (Bentley, 2006; Frei and Frei, 2011, 2013; Hodell et al., 2004; Maurer et al., 2012; Price et al., 2002; Sillen et al., 1998; Slovak and Paytan, 2011). Plant samples are generally considered to be a better sample choice across different environments and can also offer insights into the variation of the $\mathrm{Sr}$ isotope ratio with depth, as different plant samples source $\mathrm{Sr}$ from different soil depths.

3. The bioavailable $\mathrm{Sr}$ isotope ratio can also be modelled based on the bedrock lithology, age, and weath- ering rates (Bataille and Bowen, 2012; Bataille et al., 2012; Beard and Johnson, 2000). These models have shown significant potential and the next step is to assess their predictive ability across different geologic and geographic regions using direct measurements.

In many regions mineral weathering is the dominant influence on the bioavailable $\mathrm{Sr}$ isotope ratio and thus different geologic units can be differentiated. However, there are other processes including atmospheric Sr input (sea spray, dry fall), and in modern context fertilisers and other anthropogenic influences that can significantly affect the $\mathrm{Sr}$ isotope ratio. In addition, in regions with exogenic surface deposits (loess, glacial deposits) the local bioavailable $\mathrm{Sr}$ isotope ratio can be completely disconnected from the underlying geology. In conclusion, the choice of sample location and material and its value as a reference for mapping the geologic unit need to take these effects into consideration. This interpretative step will also depend on the focus of the study e.g. modern studies in contrast to archaeological studies.

Strontium isoscapes have been published on a countryscale for Mesoamerica (Hodell et al., 2004), United Kingdom (Evans et al., 2010), and Denmark (Frei and Frei, 2011, 2013), using a combination of directly sampled materials. Modelling of the bioavailable $\mathrm{Sr}$ isotope ratio has been undertaken for the contiguous USA (Bataille and Bowen, 2012; Beard and Johnson, 2000) and the circum-Caribbean region (Bataille et al., 2012). Sr data also exist as smaller-scale maps from different archaeological studies summarised in Slovak and Paytan (2011). While data is still lacking for many regions a robust approach is to combine as many different sample materials as possible to investigate their differences. Moreover, where possible, strontium isotope analyses should be undertaken in conjunction with other lines of evidence, including other isotope systems such as oxygen and lead, to validate a samples provenance. As a final note, a fundamental limitation of provenance studies is that it is only possible to disprove a source hypothesis, not to prove origin from a specific source.

\section{Data set of bioavailable Sr isotope ratios of France}

The bioavailable $\mathrm{Sr}$ isotope ratio data set of France is based on plant and soil samples. By sampling both sample types over a wide range of geologic units and large geographic regions, we expect to reliably constrain the local bioavailable $\mathrm{Sr}$ isotope ratios and gain insight into the possibly different sources of Sr to plants and soils. Ground and surface water samples would be a valuable addition to this data set and are being considered for future sample collection.

The data set presently contains 840 sample locations, covering the major geologic units of France (Fig. 1, Table 1). As only small amounts of the collected sample material have been used for our analysis we have established a large archive of plant, soil and rock samples that is available to the 


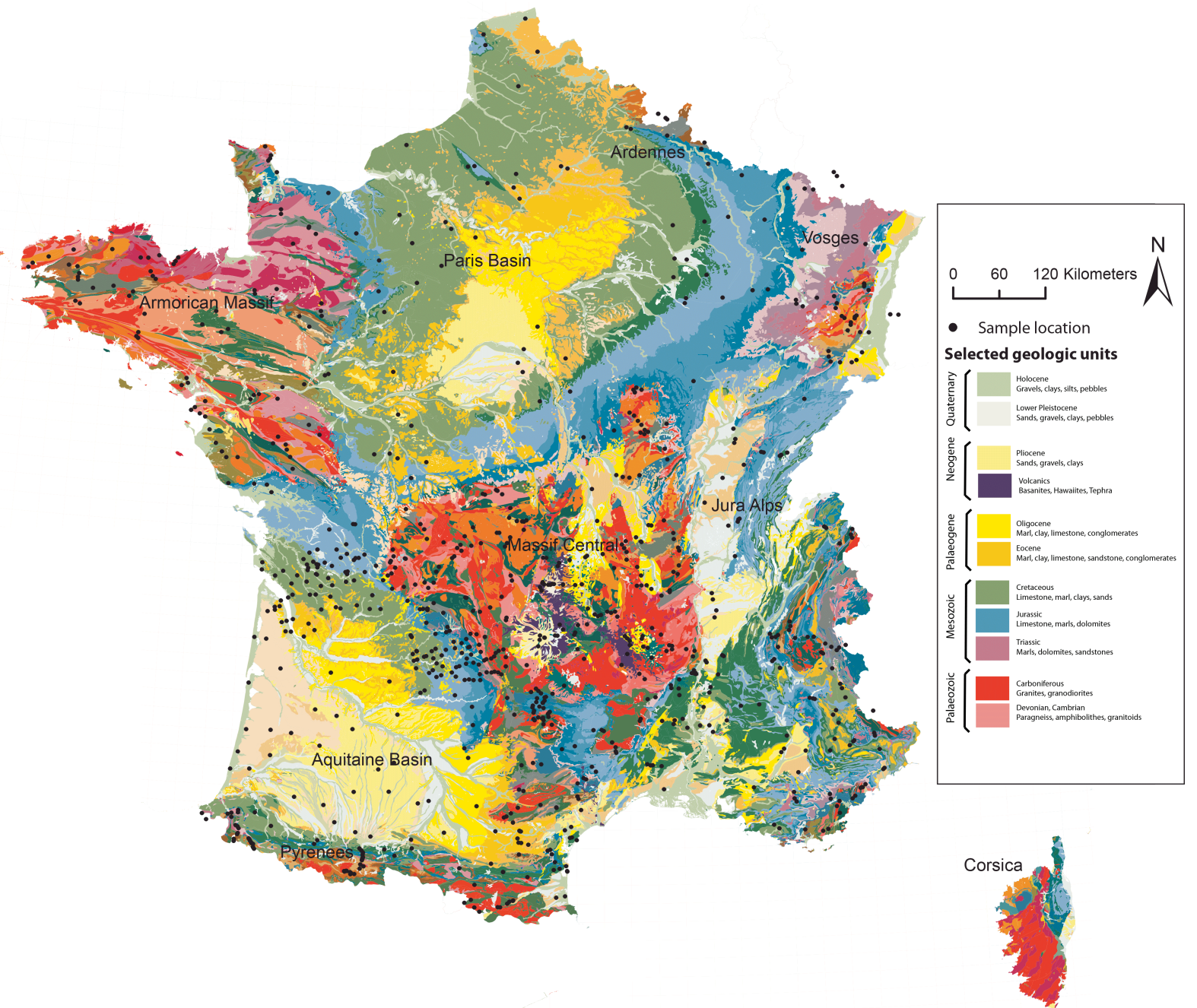

Figure 1. Map showing the sample locations (black dots) overlain on the 1:1M Geologic map of France (Chantraine et al., 2005).

scientific community for further investigation. The analysis of these samples is ongoing and new results will be added to the database as they become available with the aim of analysing all major geologic units of France within the next year. Finally, because the geology of France is varied and incorporates some of Europe's dominant geologic units, the data gathered for France might be useable to infer Sr isotope values for similar geologic regions across Europe.

\section{Methods}

\subsection{Sample collection}

The selection and density of the sample sites is based on the distribution of the geologic units on the $1: 1 \mathrm{M}$ Geologic map of France (Chantraine et al., 2005). There is a wide spacing of sample sites in sedimentary basins, where the geology does not change over large areas, and closer spacing in geologically complex regions. Some geologic units contain sev- eral very different lithologies and our sampling was aimed at covering each of these lithologies. Areas where the bioavailable $\mathrm{Sr}$ isotope ratios are likely to be detached from the bedrock geology, like coastal areas influenced by sea spray, areas covered with glacial or loess deposits, swamps and peat deposits, were targeted to investigate these processes. In addition, closely spaced samples were taken around sites of special interest, such as archaeological sites and we collected a number of samples from agricultural fields to investigate the possible influence of fertilisers in France. Typical sample sites include road cuts, outcrops, fields, areas of forest, and shallow pits. At each site, plant, soil and rock samples were collected in close proximity to each other. Each sample site was photographed and described in detail, including information about the rock, soil and plant type collected, as well as an assessment of possible recent geomorphic and anthropogenic influences. 
Table 1. Metadata available for each sample site.

\begin{tabular}{|c|c|}
\hline Sample ID & $\begin{array}{l}\text { The sample ID can be used to identify the sample in our data tables and archives. Current standard is } \\
\text { F-year-sample\#, for example F11-02 means the second sample collected in } 2011 \text {. }\end{array}$ \\
\hline Researcher & Names of the researchers collecting the samples \\
\hline Latitude, longitude, elevation & Coordinates of the sample site \\
\hline Site image & If available, a picture of the outcrop or sampling site will be shown here \\
\hline Outcrop type & We distinguish different types of outcrops. \\
\hline & $\begin{array}{l}\text { - Outcrop: a natural outcrop of rock, as far as we could identify. Not uncovered through recent } \\
\text { human activity. } \\
\text { - Road cut: along a major road, rocks unearthed by human activity. } \\
\text { - Quarry: outcrop created by human activity, often no longer in use. } \\
\text { - Field: a sample collected from a field or meadow. } \\
\text { - Turned over tree: a sample collected from or beneath a turned over tree that has excavated some } \\
\text { fresh soil layers. } \\
\text { - Shallow pit: a sample collected from a } \sim 10-20 \mathrm{~cm} \text { deep hole dug by us. }\end{array}$ \\
\hline
\end{tabular}

Setting This is a short description of our observations in the field, such as the proximity of human activities (agriculture, forest plantations) or clear indications of other recent influences.

Sample descriptions $\quad$ Field observations during sample collection, such as rock, soil and plant type and characteristics.

${ }^{87} \mathrm{Sr} /{ }^{86} \mathrm{Sr}$

Bioavailable strontium isotope ratios

Geologic setting

Summary of the geologic information from the 1 : 1M BRGM (The French Geological Survey) geologic map including the geologic region, rock type, geologic unit, major lithologies and age ranges.

\subsection{Analytical methods}

Strontium is abundant in many materials in the environment. While this is an advantage for its use as a tracer it also increases the potential of contamination during sample preparation, especially for samples with low natural Sr concentrations. The samples were transported in sealed containers to Australia and irradiated at 50 Gy by the Australian Quarantine and Inspection Service to comply with quarantine procedures. All work is carried out under clean laboratory conditions. Only ultrapure reagents are used, and blanks are monitored at each step during the laboratory procedures to check for possible contamination. A summary of the sample preparation steps is illustrated in Fig. 2 and described in detail in this section.

\subsubsection{Sample treatment}

A $\sim 30 \mathrm{~g}$ subsample of each soil sample was dried overnight at $60^{\circ} \mathrm{C}$ and then sieved through a $2 \mathrm{~mm}$ sieve. A $1 \mathrm{~g}$ aliquot was subsampled and leached by adding $2.5 \mathrm{~mL} 1 \mathrm{M}$ ammonium nitrate $\left(\mathrm{NH}_{4} \mathrm{NO}_{3}\right)$ following the protocol DIN (German Institute for Standardization) ISO (International Organization for Standardization) 19730 (2009) and shaking for $8 \mathrm{~h}$. Samples are then centrifuged at $3000 \mathrm{rpm}$ for $15 \mathrm{~min}$, the supernatant extracted $(\sim 1-2 \mathrm{~mL})$ and evaporated to dryness and then redissolved in $2 \mathrm{~mL} 2 \mathrm{M}$ nitric acid $\left(\mathrm{HNO}_{3}\right)$.
Plant samples were placed in heat resistant ceramic crucibles and ashed in an oven at $800^{\circ} \mathrm{C}$ for $8 \mathrm{~h}$. A $0.1 \mathrm{~g}$ aliquot of each sample was then digested in $1 \mathrm{~mL}$ ultrapure concentrated $\mathrm{HNO}_{3}$ for at least $1 \mathrm{~h}$, before being evaporated to dryness overnight and redissolved in $2 \mathrm{~mL} 2 \mathrm{M} \mathrm{HNO}_{3}$. A $0.1 \mathrm{~mL}$ subsample was extracted and placed in a vial with $4.9 \mathrm{~mL}$ $2 \% \mathrm{HNO}_{3}$. These solutions were then analysed using the ICP-AES (inductively coupled plasma atomic emission spectrometry) to determine $\mathrm{Sr}$ and other major and trace element concentrations. The samples are further processed by ion exchange chromatography to isolate $\mathrm{Sr}$ from other interfering elements, in particular ${ }^{87} \mathrm{Rb}$ (isobaric interference), using two sets of columns filled with Eichrom Sr specific resin (prefilter and $\mathrm{Sr}$ specific resin). In order to reach a target concentration of $\mathrm{Sr}$ in each sample volume eluted (600 $\mathrm{ng}$ in $2 \mathrm{~mL}$ ) the amount of sample added to the ion exchange columns is adjusted based on the Sr concentration determined by ICPAES. The samples were finally diluted by a factor of 4 prior to MC-ICP-MS (multi-collector inductively coupled plasma mass spectrometer) analysis to allow for reanalysis if necessary.

\subsubsection{Neptune MC-ICP-MS measurements}

$\mathrm{Sr}$ isotope ratios were measured in the Environmental Geochemistry and Geochronology Laboratory at the Research 
Table 2. Standard cup configuration and analysed masses (amu or isotope mass) employed for solution Sr isotope analysis on the Neptune MC-ICP-MS at RSES.

\begin{tabular}{lllllllll}
\hline L4 & L3 & L2 & L1 & C & H1 & H2 & H3 & H4 \\
\hline 82.152 & ${ }^{83} \mathrm{Kr}$ & 83.466 & ${ }^{84} \mathrm{Sr}$ & ${ }^{85} \mathrm{Rb}$ & ${ }^{86} \mathrm{Sr}$ & 86.469 & ${ }^{87} \mathrm{Sr}$ & ${ }^{88} \mathrm{Sr}$ \\
\hline
\end{tabular}

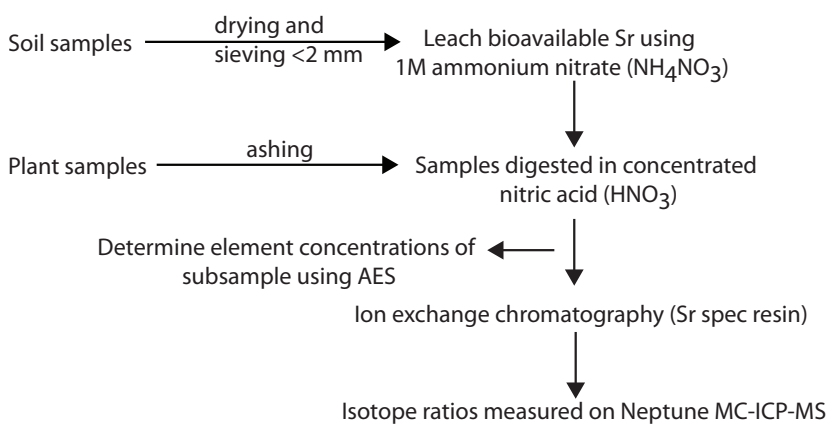

Figure 2. Overview of the preparation procedure for ${ }^{87} \mathrm{Sr} /{ }^{86} \mathrm{Sr}$ analysis of plant and soil samples.

School of Earth Sciences, ANU (The Australian National University), using a Neptune MC-ICP-MS. MC-ICP-MS was chosen over TIMS (thermal ionisation mass spectrometer) due to the requirement of high sample throughput for this project. A quartz dual cyclonic spray chamber, PFA (perfluoroalkoxy) $100 \mu \mathrm{L}$ nebuliser and standard $\mathrm{Ni}$ cones were used for sample introduction, and the instrument was tuned for maximum signal strength, stability and peak shape. The isotopes and Faraday cup configuration employed for analysis is shown in Table 2. Data reduction is performed offline in Microsoft Excel and includes $\mathrm{Kr}$ and ${ }^{87} \mathrm{Rb}$ isobar corrections, an exponential mass bias correction, and $3 \sigma$ outlier rejection.

\subsubsection{Quality control}

To assure data set precision, accuracy, reproducibility and comparability to other international data sources we record and report blank and standard analyses as a long-term reference for our laboratory in the database. Total procedural blanks vary between 50 and $250 \mathrm{pg} \mathrm{Sr}$, and were analysed by isotope dilution with an ${ }^{84} \mathrm{Sr}$ enriched isotope spike using a TRITON Plus TIMS at RSES (Research School of Earth Sciences), ANU. These blank levels represent insignificant contributions to the amount of sample $\mathrm{Sr}$ measured (i.e. $>100 \mathrm{ng}$ ). We tested the reproducibility of our analysis by running duplicate samples through the entire procedure and found differences between ${ }^{87} \mathrm{Sr} /{ }^{86} \mathrm{Sr}$ ratios measured for the same sample to be $<0.004 \%(n=42)$.

Biases between measured ${ }^{87} \mathrm{Sr} /{ }^{86} \mathrm{Sr}$ ratios in different laboratories relate to differences in instrument design, problems of resolution of mass peaks and differences in measurement protocols (Faure and Mensing, 2005). Measurements of the Sr carbonate standard SRM987 (National Institute of Stan- dards and Technology) on the Neptune MC-ICP-MS gave an average ${ }^{87} \mathrm{Sr} /{ }^{86} \mathrm{Sr}$ value of $0.71023 \pm 0.00001(n=167$, $2 \sigma)$. This is in excellent agreement with measurements of the same standard by TIMS at RSES, ANU, which gave an average ${ }^{87} \mathrm{Sr} /{ }^{86} \mathrm{Sr}$ value of $0.71023 \pm 0.00002(n=99,2 \sigma)$. It is also in agreement with the accepted ${ }^{87} \mathrm{Sr} /{ }^{86} \mathrm{Sr}$ value for SRM987 of 0.71025 (Faure and Mensing, 2005), and is within uncertainty of the original, albeit imprecise, certified value of $0.71034 \pm 0.00026$ (Moore et al., 1982).

To assess the comparability of our data set we carried out a blind test on a grazing soil standard from the GEMAS project (Geochemical Mapping of Agricultural and Grazing Land Soil). Measurements at RSES gave an average value of $0.70631 \pm 0.00005(n=10,2 \sigma)$ which is in agreement with the GEMAS value of $0.70638 \pm 0.00003(n=39,2 \sigma)$ (Reimann et al., 2013). For future comparability studies we have commenced measuring an in-house soil standard which will be made available upon request.

\section{Database architecture}

The IRHUM (Isotopic Reconstruction of Human Migration) database is a web platform to explore and share strontium isotope data sets and data products. It is built upon a highly flexible, open source software stack (Opengeosuite, Geonode) maintained by Boundless (http://boundlessgeo.com) and follows common web standards. Its current functionality allows the user to explore our data sets, upload their own data, and create basic isotope maps. It is also possible to connect to an external WMS server to load background data such as geological and soil maps. In addition to the spatial isotope data the IRHUM website stores metadata and allows the user to upload documents to describe their project and methods. This will enable others to assess the suitability of specific data for their study. Finally, the data can be exported in a variety of formats (.csv, .kml, .shp, .pdf) for GIS analysis. In summary, IRHUM provides easy access to data sets, which facilitate the reuse of data and collaborative development of isotope maps at a variety of scales.

\section{Data access}

The data set can be viewed and downloaded on the IRHUM webpage (http://www.irhumdatabase.com or http: //www.rses.anu.edu.au/research-areas/archaeogeochemistry/ tracing-human-migration). The full data set is also available through the Pangaea data repository 
(doi:10.1594/PANGAEA.819142). Updates of the data set are added to the IRHUM webpage as soon as they become available and will be passed on to the Pangaea data repository at the end of the project in 2014.

Acknowledgements. The authors thank the editor and two anonymous reviewers for their constructive comments on the manuscript. Furthermore, we would like to thank P. Rossi, P. Courtaud, C. Boel and M. Huyskens, for their immense help on the design and execution of the sampling campaign. We thank G. Mortimer and the engineering workshop at RSES for their support with the technical parts of this project and the Geonode community for their assistance implementing the database. Funding was provided by ARC DP110101415 (Grün, Spriggs, Armstrong, Maureille and Falguères): Understanding the migrations of prehistoric populations through direct dating and isotopic tracking of their mobility patterns.

Edited by: A. Demény

\section{References}

Bataille, C. P. and Bowen, G. J.: Mapping $87 \mathrm{Sr} / 86 \mathrm{Sr}$ variations in bedrock and water for large scale provenance studies, Chem. Geol., 304-305, 39-52, doi:10.1016/j.chemgeo.2012.01.028, 2012.

Bataille, C. P., Laffon, J., and Bowen, G. J.: Mapping multiple source effects on the strontium isotopic signatures of ecosystems from the circum-Caribbean region, Ecosphere, 3, 1-24, 2012.

Beard, B. L. and Johnson, C. M.: Strontium isotope composition of skeletal material can determine the birth place and geographic mobility of humans and animals, J. Forensic Sci., 45, 1049-61, 2000.

Bentley, R. A.: Strontium Isotopes from the Earth to the Archaeological Skeleton: A Review, J. Archaeol. Method Th., 13, 135187, doi:10.1007/s10816-006-9009-x, 2006.

Capo, R. C., Stewart, B. W. and Chadwick, O. A.: Strontium isotopes as tracers of ecosystem processes: theory and methods, Geoderma, 82, 197-225, 1998.

Chantraine, J., Chêne, F., Nehlig, P., and Rabu, D.: Carte géologique de la France à 1/1 000000 6e édition révisée 2003, BRGM, Orléans, 2005.

DIN: ISO 19730 (2009-07) Soil quality - Extraction of trace elements from soil using ammonium nitrate solution (ISO 19730:2008), DIN, 2009.

Evans, J. A., Montgomery, J., Wildman, G. and Boulton, N.: Spatial variations in biosphere $87 \mathrm{Sr} / 86 \mathrm{Sr}$ in Britain, J. Geol. Soc. London, 167, 1-4, doi:10.1144/0016-76492009-090, 2010.

Faure, G. and Mensing, T. M.: Isotopes: Principles and Applications, 3rd Edn., John Wiley and Sons Inc., Hoboken, New Jersey, 2005.

Frei, K. M. and Frei, R.: The geographic distribution of strontium isotopes in Danish surface waters - A base for provenance studies in archaeology, hydrology and agriculture, Appl. Geochem., 26, 326-340, doi:10.1016/j.apgeochem.2010.12.006, 2011.
Frei, R. and Frei, K. M.: The geographic distribution of Sr isotopes from surface waters and soil extracts over the island of Bornholm (Denmark) - a base for provenance studies in archaeology and agriculture, Appl. Geochem., 38, 147-160, doi:10.1016/j.apgeochem.2013.09.007, 2013.

Hobson, K. A., Barnett-johnson, R., and Cerling, T.: Using Isoscapes to Track Animal Migration, in Isoscapes, edited by: West, J. B., Bowen, G. J., Dawson, T. E., and Tu, K. P., 273-298, Springer, the Netherlands, 2010.

Hodell, D. A., Rhonda, Q. L., Brenner, M., and Kamenov, G.: Spatial variation of strontium isotopes $(87 \mathrm{Sr} / 86 \mathrm{Sr})$ in the Maya region: a tool for tracking ancient human migration, J. Archaeol. Sci., 31, 585-601, doi:10.1016/j.jas.2003.10.009, 2004.

Kelly, S. and Heaton, K.: Tracing the geographical origin of food: The application of multi-element and analysis, Trends Food Sci. Tech., 16, 555-567, doi:10.1016/j.tifs.2005.08.008, 2005.

Maurer, A.-F., Galer, S. J. G., Knipper, C., Beierlein, L., Nunn, E. V., Peters, D., Tütken, T., Alt, K. W., and Schöne, B. R.: Bioavailable $87 \mathrm{Sr} / 86 \mathrm{Sr}$ in different environmental sampleseffects of anthropogenic contamination and implications for isoscapes in past migration studies, Sci. Total Environ., 433, 216-29, doi:10.1016/j.scitotenv.2012.06.046, 2012.

Moore, L. J., Murphy, T. J., Barnes, I. L., and Paulsen, P. J.: Absolute Isotopic Abundance Ratios and Atomic Weight of a Reference Sample of Strontium, J. Res. Natl. Bur. Stand., 87, 1-8, 1982.

Price, T. D., Burton, J. H., and Bentley, R. A.: The Characterization of Biologically Available Strontium Isotope Ratios for the Study of Prehistoric Migration, Archaeometry, 44, 117-135, doi:10.1111/1475-4754.00047, 2002.

Reimann, C., Birke, M., Demetriades, A., Filzmoser, P., and O'Connor, P.: Chemistry of Europe's agricultural soils. Geologisches Jahrbuch (Reihe B), Part A, Schweizerbarth, Stuttgart, 2013.

Shand, P., Darbyshire, D. P. F., Love, A. J., and Edmunds, W. M.: Sr isotopes in natural waters: Applications to source characterisation and water-rock interaction in contrasting landscapes, Appl Geochem., 24, 574-586, doi:10.1016/j.apgeochem.2008.12.011, 2009.

Sillen, A., Hall, G., Richardson, S., and Armstrong, R.: 87Sr/86Sr ratios in modern and fossil food-webs of the Sterkfontein Valley: Implications for early hominid habitat preference, Geochim. Cosmochim. Ac., 62, 2463-2473, doi:10.1016/S00167037(98)00182-3, 1998.

Slovak, N. M. and Paytan, A.: Application of Sr Isotopes in Archaeology, in Handbook of Environmental Isotope Geochemistry, edited by: Baskaran, M., p. 951, Springer Berlin Heidelberg, 2011.

Voerkelius, S., Lorenz, G. D., Rummel, S., Quétel, C. R., Heiss, G., Baxter, M., Brach-Papa, C., Deters-Itzelsberger, P., Hoelzl, S., Hoogewerff, J., Emmanuel, P., Marleen, V. B. and Henriette, U.: Strontium isotopic signatures of natural mineral waters, the reference to a simple geological map and its potential for authentication of food, Food Chem., 118, 933-940, doi:10.1016/j.foodchem.2009.04.125, 2010. 